\title{
A framework for profiling the characteristics of risk governance in natural hazard contexts
}

\author{
G. Walker ${ }^{1}$, F. Tweed ${ }^{2}$, and R. Whittle ${ }^{1}$ \\ ${ }^{1}$ Lancaster Environment Centre, Farrer Avenue, Lancaster University, Lancaster, LA1 4YQ, UK \\ ${ }^{2}$ Geography, Staffordshire University, Leek Road, Stoke-on-Trent, Staffordshire, ST4 2DF, UK
}

Correspondence to: G. Walker (g.p.walker@lancaster.ac.uk)

Received: 5 February 2013 - Published in Nat. Hazards Earth Syst. Sci. Discuss.: 21 May 2013

Revised: 20 October 2013 - Accepted: 5 December 2013 - Published: 30 January 2014

\begin{abstract}
Over recent decades there have been moves away from traditional forms of government towards broader practices of "governance". These moves are as relevant to the handling of natural hazards as they are to other societal concerns. Key characteristics of such changes include the emergence of multi-level governance processes, shifts away from the exercise of centralised authority towards the involvement and collaboration of a multiplicity of actors, the creation of new forms of authority and control, and changing distributions of responsibilities between the state and other actors. However, the extent to which these shifts have taken place across the varied national contexts in Europe and can be observed specifically in relation to the governance of natural hazards is not at all clear. Such developments may also be evaluated in different ways; where some might see progressive reforms, others might see damaging undermining of established arrangements.

In this paper, we propose a risk governance profiling framework that can be used to draw out the key characteristics of the ways in which natural hazards are governed in a particular governance setting. The framework can be flexibly applied in relation to a specific hazard and national, regional or local context, and enables qualitative profiling across a spectrum of eight key governance characteristics. Past trends and likely future changes can also be represented. We discuss the formulation of this framework as well as giving examples of profiles for different hazards in different parts of Europe. We suggest ways in which comparisons can be made between governance profiles, providing a stimulus and focus for debate and discussion around the trends of change in governance practice that have been, and are continuing, to take place.
\end{abstract}

\section{Introduction}

Risks are always managed within a broader context of relationships between governments, citizens, civil society and private business; relationships that shift and evolve over time with changing political currents and economic conditions. Over the past thirty years or so, moves away from government towards a broader practice of "governance" have been identified (Rhodes, 1997; Bevir and Rhodes, 2003), a shift that is potentially as relevant to the handling of natural hazards as it is to other societal concerns such as economic regeneration or transport. The characteristics of what has been termed "new governance" include the emergence of multilevel governance processes and the "hollowing out" of the power of the nation state; moves away from the exercise of centralised authority towards the involvement of a multiplicity of private sector and civil society actors; the creation of new forms of authority and control; and changing distributions of responsibilities between the state and other actors, including individual citizens (Walker et al., 2010).

In the case of natural hazards in a European context, we can observe examples of how each of these generic emerging governance characteristics have played into the reform of structures and strategies of hazard and risk management, both in EU level provisions and in the measures of particular nation states and regions. However, there is also much variation in the extent to which these characteristics have taken hold - for example, in the extent of multi-stakeholder participation, or the degree of individualisation of responsibility for hazard protection - across the complex and varied European natural hazard landscape. There is also an undoubted need for debate and discussion around how far these new governance 
characteristics should be integrated into the policy and practice of natural hazard management; where some might see progressive reforms, others might see damaging undermining of established principles of democratic practice and equality of treatment.

In this paper, we propose a framework for profiling risk governance practice in relation to characteristics identified in both the general governance literature and in more specific work on risk governance. This framework enables a simple, qualitative representation and evaluation of key characteristics of natural hazard governance to be produced that can be applied in a flexible way to a variety of forms of hazard and governance setting. We argue that this profiling framework is of value in (i) drawing out the governance differences that exist between different settings in Europe and between the different forms of natural hazard that are faced across the European space; and (ii) providing a productive stimulus and focus for debate and discussion around the trends of change in governance practice that have been, and are continuing, to take place. Whilst various profiling tools have been developed in relation to natural hazard concerns, these are typically focused on mapping vulnerability or resilience characteristics (e.g. Morrow, 1999; O’Brien et al., 2004; Fussel, 2007). We have not been able to identify any readily applicable framework that is concerned with profiling governance approaches or arrangements and that can be applied in the flexible ways that we have envisaged.

In the first part of the paper, we summarise the key shifting attributes of governance and how these pertain to natural hazards in Europe; these key attributes directly inform the content of the profiling framework. In the second part of the paper we explain the development of the framework and discuss how this can be used in processes of discussion and debate in different risk governance contexts.

\section{From government to governance}

The move from government to governance first began to be observed during the 1980s and 1990s, particularly in a European context during a period of scaling down of the size and remit of the public sector (Rhodes, 1997; Walker et al., 2010). Governance is typically captured by a set of distinctive characteristics. Most crucial is a move away from the exercise of centralised governmental control and towards the emergence of multiple governance actors, networks and partnerships in place of a single sovereign authority (Rhodes, 1997), such that the state is no longer necessarily the main player in the system (Rosenau, 2004; Ahrens and Rudolph, 2006). This means that there will be increasing interdependence between actors and agencies, a need to negotiate shared goals and some degree of blurring of boundaries between private, public and voluntary sectors. Governance is characterised by different state-society relationships and responsibilities, involving co-resourcing, co-decision and co- delivery, with the state becoming increasingly dependent on other actors to deliver services and to implement policies (Bevir and Trentmann, 2007). The "hollowing out of the nation state", to which governance theorists often refer, captures the dissolution of linear chains of command associated with different tiers of government (local, regional, national, international) and the emergence of more complex structures based on networks involving social groups, private companies, policy makers, civic and voluntary organisations and agencies, which can work interdependently and communicate across boundaries at different levels (Rhodes, 1997).

With these changes have come new forms of authority and control. Traditional techniques of coercion and enforcement are replaced by arguably more subtle tactics of diplomacy and management. In governance, the exercise of authority still occurs, but it involves the development and use of a broader range of strategies and implementation tools including informal agreements, negotiated solutions to problems and initiatives aimed at shaping people's expectations, norms and habits (Rosenau, 2004).

These observed key elements of the shift from government to governance have prompted much discussion and debate by researchers, practitioners and policy makers. There have been suggestions that the changing nature and increasing prominence of some global problems, such as climate change, terrorism and financial crises inherently require new forms of collaborative and distributed governance process as they cannot be addressed by regional or national agencies or states working in isolation (e.g. Beck, 1992; Bulkeley, 2001; Marks and Hooghe, 2004; Beck, 2006). Positive perspectives on the emergence of governance also emphasise that the changes can increase democracy and empower individuals and groups through increased participation and the recognition of diversity through plurality of perspectives (Marks, 2004; Hajer and Versteg, 2005; Rosenau, 2004). However, critics of the "new governance" argue that power relations still play an intrinsic role in policy negotiations and that whilst participation can give an impression of transparency, engagement and interaction, decision-making still rests in the hands of a few influential individuals or organisations (Bache and Flinders, 2004). There are also major debates about issues of accountability and justice, both of which formerly rested with elected political parties, but are now becoming increasingly opaque or elusive as a consequence of the distribution of management responsibility to the private sector or to un-elected bodies and the difficulties in stimulating, coordinating and adjusting activities amongst and between different actors (Bovens, 1990; Ahrens and Rudolph, 2006; Bevir, 2007).

Such evaluations of governance practice can be discussed in rather sweeping terms, but in practice there are considerable differences between countries and regions in the extent to which the key attributes of the shift from government to governance have emerged, and in the extent to which they have permeated different practices, processes and domains 
Table 1. Guidance on the eight risk governance characteristics captured in the risk governance characterisation template.

\begin{tabular}{|c|c|}
\hline strong national policy framework & weak national policy framework \\
\hline $\begin{array}{l}\text { There is a clear, well specified and comprehensive policy frame- } \\
\text { work in place at a national level that is effective in achieving its } \\
\text { objectives }\end{array}$ & $\begin{array}{l}\text { There is little in the way of a national policy framework, poli- } \\
\text { cies are poorly specified or missing and are highly ineffective in } \\
\text { achieving their objectives }\end{array}$ \\
\hline strong role for regional institutions & weak role for regional institutions \\
\hline $\begin{array}{l}\text { There are clear roles for regional institutions who play an im- } \\
\text { portant part in implementing national policy and/or specifying } \\
\text { effective regional policies }\end{array}$ & $\begin{array}{l}\text { There is very little or no role for regional institutions, which } \\
\text { may not exist within the political system }\end{array}$ \\
\hline strong local/municipal role & weak local/municipal role \\
\hline $\begin{array}{l}\text { Local authorities or municipalities have a clear and important } \\
\text { role in implementing national/regional policy and/or in specify- } \\
\text { ing their own local strategies and responses }\end{array}$ & $\begin{array}{l}\text { There is very little role for local authorities or municipalities, } \\
\text { and/or what they do is largely ineffective }\end{array}$ \\
\hline major responsibility on those at risk to protect themselves & minor responsibility on those at risk to protect themselves \\
\hline $\begin{array}{l}\text { Households, businesses or others who are at risk are largely } \\
\text { expected to take action and commit resources to protect them- } \\
\text { selves from hazards. There is little responsibility for, or expecta- } \\
\text { tion of, input or support from government or other organisations }\end{array}$ & $\begin{array}{l}\text { Households, businesses or others who are at risk are not ex- } \\
\text { pected to take any significant action to protect themselves from } \\
\text { hazards. The government or other organisations primarily have } \\
\text { the responsibility to provide protection and minimise risks }\end{array}$ \\
\hline strong culture of multi-stakeholder participation & weak culture of multi-stakeholder participation \\
\hline $\begin{array}{l}\text { Many different stakeholders and organisations are involved in } \\
\text { collaborative partnership working, they have opportunities to } \\
\text { participate and have their inputs to decision-making }\end{array}$ & $\begin{array}{l}\text { There is very little or no collaboration between government and } \\
\text { stakeholders. There are very few opportunities for participation } \\
\text { and decision- making is closed rather than open }\end{array}$ \\
\hline high reliance on segmented and marketised insurance & low reliance on segmented and marketised insurance \\
\hline $\begin{array}{l}\text { Insurance costs for the hazard involved are strongly related to } \\
\text { the degree of risk faced by a householder or business. There is a } \\
\text { substantial difference in insurance costs between high and low } \\
\text { risk locations }\end{array}$ & $\begin{array}{l}\text { Insurance costs for the hazard involved are not at all related to } \\
\text { the degree of risk faced by a householder or business. There } \\
\text { is no difference in insurance costs between high and low risk } \\
\text { locations }\end{array}$ \\
\hline extensive public risk communication & very little public risk communication \\
\hline $\begin{array}{l}\text { There is substantial, frequent and effective communication with } \\
\text { the public }\end{array}$ & $\begin{array}{l}\text { There is very little, infrequent and ineffective communication } \\
\text { with the public }\end{array}$ \\
\hline good balance between governance tasks and available resources & imbalance between governance tasks and availableresources \\
\hline $\begin{array}{l}\text { Organisations involved in managing the hazard are well re- } \\
\text { sourced and as a consequence are able to undertake their role } \\
\text { effectively }\end{array}$ & $\begin{array}{l}\text { Organisations involved in managing the hazard are very poorly } \\
\text { resourced and are as a consequence not able to undertake their } \\
\text { role effectively }\end{array}$ \\
\hline
\end{tabular}

of state policy and action. Techniques for revealing rather than subsuming such variation and for promoting debate about changes in governance policy and practice are arguably therefore of increasing importance.

\section{Governance of risks from natural hazards in Europe}

The governance of risks from natural hazards is the domain of policy and action in which we are particularly interested in this paper. As more communities, property and infrastructure are exposed to natural hazards, and as greater complexity in physical, social, cultural and systemic forms of vulnerability are produced, hazardous events have been seen to become more likely to evolve into disasters (e.g. Pelling, 2003a, b; Turner et al., 2003; Cannon, 2006). Such escalations of disaster vulnerability have emphasised the need to find better ways of living with risk and in response we have seen the emergence of some of the governance shifts outlined above.

The management of natural hazards has always involved the participation of a variety of actors operating at different levels beyond those in the public sector. Emergency and disaster response activities in particular, are characterised by co-ordination between a range of public services and voluntary and community organisations (Pearce, 2003; Ahrens 
and Rudolph, 2006; Walker et al., 2010). However, there has been recent recognition of the need for new forms of collaboration and partnership-working on risk issues that are symptomatic of new governance arrangements. Across different hazard and national contexts we can accordingly observe greater provision for the participation of a wider range of private, non-governmental organisations and community stakeholders and the development of new roles in hazard and risk management (e.g. Christoplos et al., 2001; Kuhlicke et al., 2011). New models of governance of natural hazards can also be seen in the development of regional and local resilience forums and action groups, which integrate a range of non-governmental, public and private actors and emphasise those at risk taking greater responsibility for their own protection; characterised by Medd and Marvin (2005) as a move towards the "governance of preparedness". Risk communication and risk education have the potential to play key roles in these groups and networks, but are not always developed or effective in practice (e.g. Komac et al., 2010; Höppner et al., 2012).

The emergence of multi-level governance processes and practices has also become increasingly apparent. At an international scale, this is evidenced by co-operation and coordination strategies and organisations; for example, the Global Disaster Information Network, the United Nations International Strategy for Disaster Reduction (2005) and the Hyogo Framework for Action 2005-2015. The European Union has also become increasingly involved in natural hazard governance through the development of funding and cooperation mechanisms for large-scale emergency responses and by establishing pan-European provisions in the Floods Directive and the Water Framework Directive (Walker et al., 2010; Kuhlicke et al., 2011). Examples of networks that have a role to play in risk governance include the European Union Mediterranean Disaster Information Network, which makes research results and information available to the disaster science community and the recent Academic Network for Disaster Resilience to Optimise Educational Development (ANDROID), which aims to promote co-operation and innovation across European higher education environments.

Shifts of responsibility away from the state have been increasingly associated with approaches that emphasise social capacity building, adaptation and resilience rather than costly structural and technical mitigation schemes (Walker et al., 2010; Kuhlicke et al., 2011). In a European context, this has chiefly been evident in the management of flooding and water scarcity. Public strategies and policy initiatives that try to encourage businesses and householders to make buildings more flood-resistant (e.g. Defra, 2008) are symptomatic of governance changes that transfer actions and costs to those at risk, whilst flood policy is still set by government. In the context of water scarcity, emphasis on demand management, changing behaviours and expectations and the development of techniques of drought-sensitive farming has gone hand-inhand with the more traditional hard engineering solutions of reservoir and de-salinisation plant construction (e.g. Chappells and Medd, 2007; Walker et al., 2010). Hazard related insurance cover for homes and businesses has also been increasingly at issue with the socialised systems characterising arrangements for example in France and Belgium that collectively share the burden of disaster insurance, contrasting with the more individualised systems (for example in the UK) that strongly marketise and segment insurance cover, to the point that those at risk can struggle to afford escalating premiums, or, in some cases, to obtain insurance cover at all (J. O'Neill and M. O'Neill, 2012).

It is therefore possible to identify a number of changes in the management of risks from natural hazards in Europe that parallel the emergence and development of governance processes more generally. However, these are not universal features of the ways in which risks from natural hazards are now being governed, and we should expect considerable variation across the full diversity of European national contexts. The wider evolving economic environment and its differential effects are also important to take into account, given that the severe credit crunch and austerity measures have in some European countries denuded the public sector of funding and created sometimes enormous pressures on the budgets of departments and agencies involved in hazard governance. In any contemporary evaluation of governance practice, the availability of resources in relation to allocated responsibilities is therefore an important element, and may itself underpin the drive towards some of the new governance characteristics that we have outlined.

\section{Developing a framework for profiling risk governance}

The discussion up to this point has distilled some of the key characteristics of the shift from government to governance and their applicability to natural hazard contexts. These characteristics have informed the content of the profiling framework to be outlined in the rest of the paper, which was developed as part of the learning achieved through the $3 \mathrm{yr}$ CapHaz-Net project (Kuhlicke et al., 2012). Within this EUfunded "Coordination Action" a series of workshops were organised in which project researchers, external experts, practitioners and stakeholders were involved. The first phase of the project involved three thematic meetings to explore the social and social capacity dimensions of natural hazards and disasters.

Knowledge acquired from the first phase of the project was then contextualised by focusing on regional and local practices of hazard mitigation and adaptation and on different approaches for social capacity building across Europe. Regional workshops on droughts and heat-related hazards, alpine hazards and river catchment flooding were held in order to better understand the respective regional cultures of risk and risk governance. Discussion highlighted key similarities and differences as well the impact of transitions in 
central and eastern Europe and recent economic and political upheaval across the continent. The risk governance profiling framework emerged from knowledge sharing, debate and discussion at these workshops as well as from the review outlined in the previous section.

We trialled the first version of the framework at the final CapHaz-Net workshop attended by project members and invited experts from across Europe. This involved a focus group discussion of the framework with participants experimenting with producing a governance profile for a hazard and governance context with which they were familiar. It was explained that the aim was to capture, in relatively simple and immediate terms the variability and dynamism of governance practice, and that we were interested in their qualitative judgements rather than in the generation of a "correct" profile. We concluded that whilst the broad idea and format of the framework was effective, further development was necessary to add to and clarify the governance characteristics. A second and final version was then produced particularly to better capture both contextual variability and change over time.

The final version of the profiling framework enables

- any chosen national, regional or local natural hazard governance context to be profiled against a set of eight key governance characteristics;

- the current situation for each of the eight governance characteristics to be indicated by positioning a point along a spectrum with contrasting "extremes" at either end;

- the direction and strength of past and expected future change either towards or away from the present situation to be indicated.

The eight governance characteristics (numbered in brackets and each featuring in the earlier review discussion) address

- governance scale and its distribution between national (1), regional (2) and local levels (3), with a spectrum from weak to strong in each case;

- how much those at risk are expected to be responsible for protecting themselves, with a spectrum from major responsibility to minor responsibility (4);

- the extent and culture of stakeholder participation in the governance system (5), with a spectrum from high to low;

- the type of insurance provision in place in terms of how much this relies on a marketised and segmented approach, with a spectrum from high to low reliance (6);

- the extent of communication with the public about risks (7), with a spectrum from high to low;
Risk Governance Characterisation Template

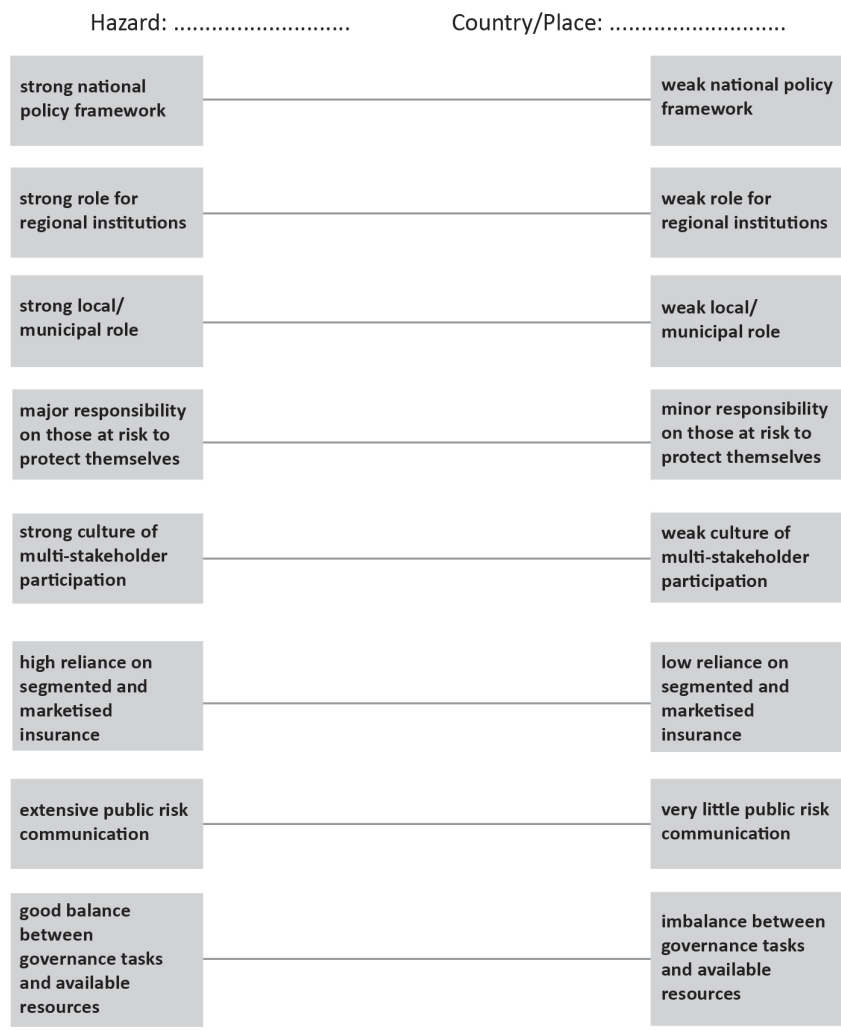

Fig. 1. Risk governance characterisation template.

- the degree of balance between governance tasks and the availability of resources for such tasks to be carried out (8), with a spectrum from a good balance to an imbalance.

These provide a set of broad categories that can be applied in a generic way for different hazards. A blank risk governance characterisation template is presented in Fig. 1, whilst Table 1 reproduces guidance notes which explain more about the end points of the spectrum for each of the eight governance characteristics. As shown in Figs. 2 to 7, users identify the current perceived position along the relevant spectrum for each risk governance characteristic, and then join these up to create a diagrammatic profile. Arrows can then be added to indicate past and predicted future dynamics in risk governance; arrows pointing towards the current position are used to indicate the direction and extent of change (if any) over the last 5 yr. Arrows pointing away from the current position indicate shifts (if any) expected in the future, again over an approximately $5 \mathrm{yr}$ time span. If there has been a lot of change the arrow will be longer as it will start from further away from the current position; if there has been less change it will be shorter and start from closer to the current position.

The result is a visualised governance profile that is inherently qualitative and judgemental in character; subject to the 
Risk Governance Characterisation Template

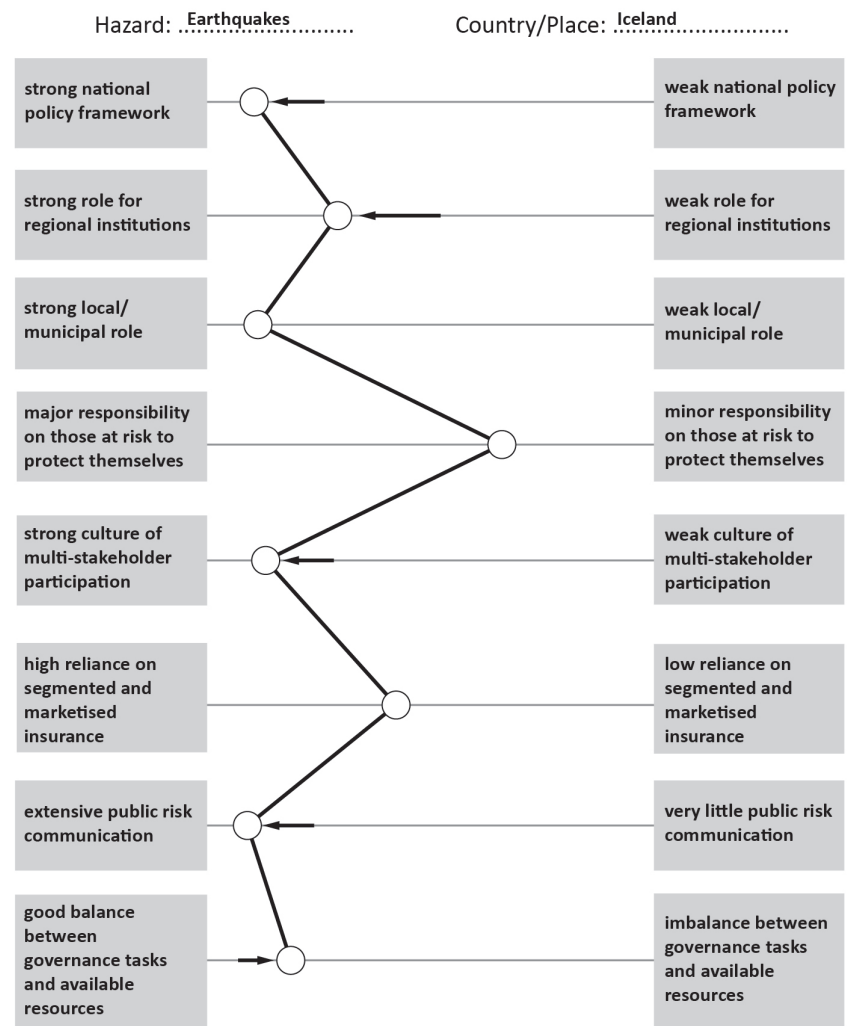

Fig. 2. Example of risk governance profile - Earthquakes in Iceland.

perspective and evaluation of the person creating the profile, rather than measurable in any absolute fashion. It is designed to be relatively simple to complete and to be flexible enough to be used in many different settings and for different forms of hazard, so the characteristics that it is profiling are only described at a general level. During the trial stage of the development of the governance profile, some workshop participants argued that the spectrum for each characteristic should be specified, (for example, on a 1-5 scale), with each graduation precisely defined. However we have resisted this move in order to maintain the qualitative and flexible nature of the framework as this is essential to the ways in which we envisage its application and usefulness. It is to examples of its application that we therefore now turn.

\section{Applying the framework}

As outlined above, the risk governance profiling framework enables any chosen national, regional or local natural hazard governance context to be profiled against key governance characteristics. The framework can be used to focus on just one hazard/setting context, or to make comparisons of various forms. We see the value of comparison as raising questions about why similarities or differences exist between pro-
Risk Governance Characterisation Template

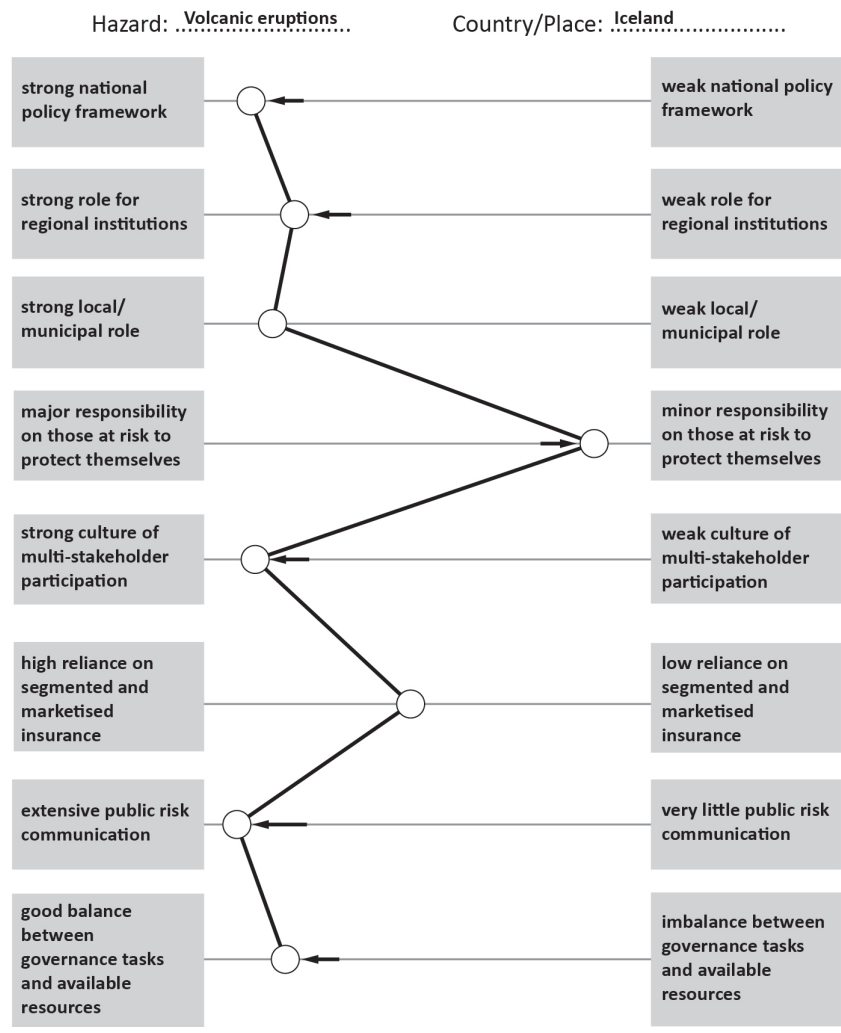

Fig. 3. Example of risk governance profile - Volcanic eruptions in Iceland.

files. Comparisons can, for example, be made between governance profiles for the same hazard across different contexts, e.g. for earthquake hazards in different national systems; or between hazards in the same context, e.g. for landslides, earthquakes and floods within the same region or nation. Each of these could be productively used in exchanges and discussions between governance communities at international, national or regional levels. Comparisons could also be made between the profiles produced by different users or stakeholders for the same hazard and place, e.g. by the various parties with interests in local flood governance. Here we see the qualitative nature of the risk profiling tool as particularly useful, enabling users to each produce their own version and then compare and discuss their similar or contrasting perspectives, maybe then moving to collaboratively generate a common profile. This could be particularly valuable when there are clear divisions of opinion that need to be better understood, or pressures for change that are destabilising existing governance arrangements.

To begin to demonstrate the different ways in which the profiling tool can be used, we asked a range of people involved with knowledge of natural hazard governance in different parts of Europe to complete a profile, providing them with a set of instructions and guidance notes. Their 


\section{Risk Governance Characterisation Template}

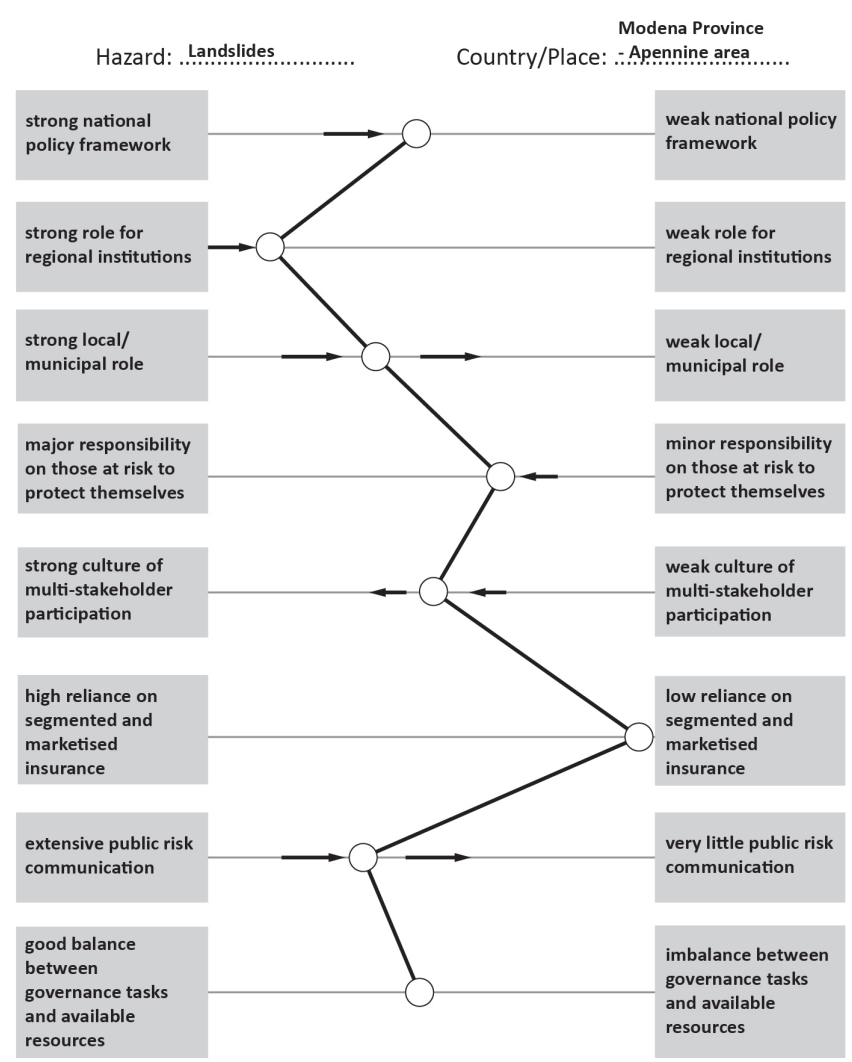

Fig. 4. Example of risk governance profile - Landslides in the Province of Modena, Italy.

completed profiles are provided as examples, and briefly discussed below.

1. The governance of volcanoes and earthquakes in Iceland from a national perspective: as an example of how the profiling tool can be used collaboratively and to compare between hazards in the same governance context, three staff working in the monitoring and forecasting division of the national Icelandic Meteorological Office (IMO) discussed the governance of risks arising from earthquakes and volcanic eruptions in Iceland and jointly completed a profile for each hazard (see Figs. 2 and 3). Iceland has an established culture of monitoring, researching, educating, forecasting and warning with respect to volcanic eruptions and earthquakes and a strong national policy framework has been in existence for some time. As a consequence, we can see that there are strong commonalities in the completed profiles for both of these hazards, with differences only apparent in the extent to which those at risk are expected to protect themselves, the strength of regional institutions and the direction of trend of change in resource availability. The three staff found that collaborating together in generating the profiles
Risk Governance Characterisation Template

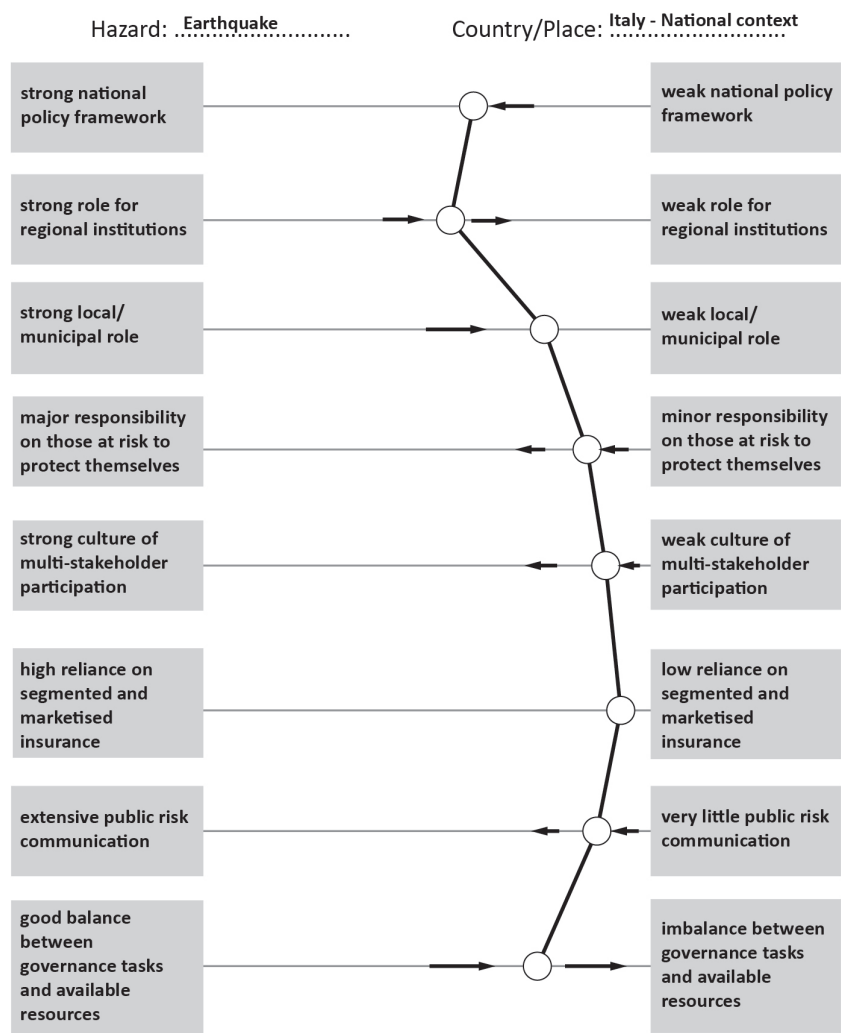

Fig. 5. Example of risk governance profile - Earthquakes in Italy.

made them reflect on the governance arrangements that were in place, their adequacy and the pressures for change that were being experienced.

2. The governance of landslides and earthquakes in Italy at different scales: a second example of a comparison between hazards was undertaken by two experienced researchers who were able to complete profiles for, respectively, the governance of landslides in the Province of Modena in the Appennines and the governance of earthquakes at a national level (see Figs. 4 and 5). The two profiles are quite strikingly different in this case with earthquake governance seen to be generally weak, particularly at a local level, with similarly weak cultures of stakeholder participation and risk communication. Landslide governance in contrast is seen to have a particularly strong regional profile, a trend towards greater stakeholder participation and established practices of extensive risk communication, although these are diminishing. In both cases there is a similar insurance regime, an increasing responsibility on those at risk to protect themselves and, in the earthquake case, a strong trend towards diminishing resources committed to governance tasks. Revealing these similarities and differences raised questions 
Risk Governance Characterisation Template

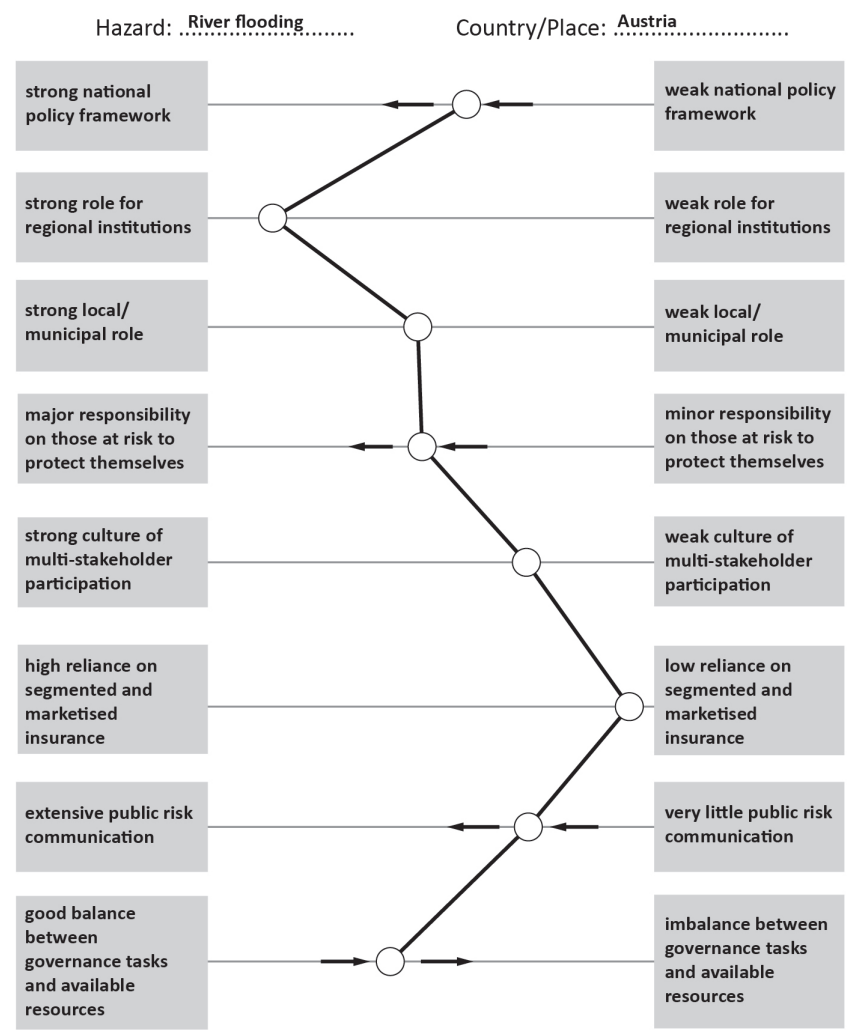

Fig. 6. Example of risk governance profile - River flooding in Austria.

about why they exist, how the regional competence for landslides is perhaps particularly effective in promoting involvement and communication, and how pressures are pushing for change in a different direction.

3. The governance of river flooding in Austria and the UK from a regional perspective: the third example (see Figs. 6 and 7) keeps the form of hazard constant (river flooding) but changes the national context, with profiles completed by two hazard researchers for Austria and the UK. Here some quite striking differences emerge. In Austria there is a strong role for regional governance, reflecting the wider structuring of the political system, whereas in the UK the regional level has always been weaker and has been further denuded by the removal of regional bodies by the current administration. There is a stronger pattern of multi-stakeholder participation in the UK, reflecting the development of resilience forums and cross-agency working, and between the two countries there is a big contrast in insurance arrangements. In the UK there is a strongly marketised system with big differentials in insurance costs and consequences for affordability, in Austria (for households at least) a socialised system remains in
Risk Governance Characterisation Template

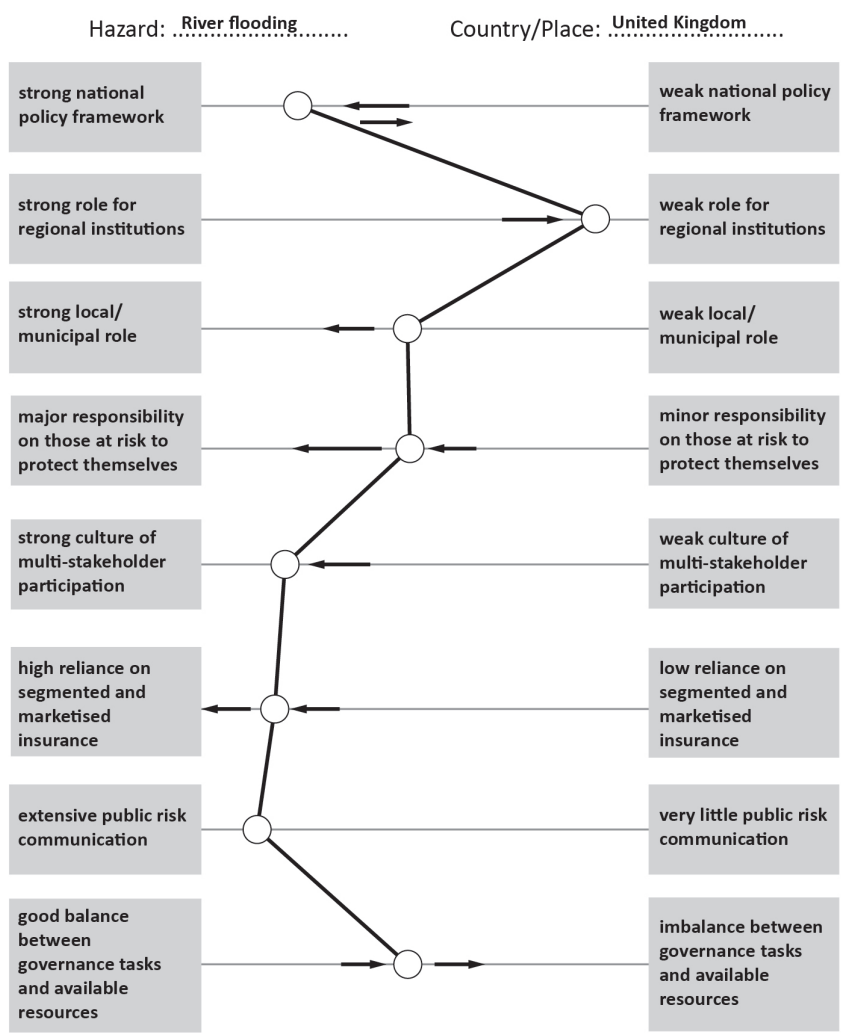

Fig. 7. Example of risk governance profile - River flooding in the UK.

place in which flooding is a shared risk. Commonalities include both countries seeing moves towards more responsibility being given to those at risk to protect themselves and clear pressures on the availability of resources for flood risk governance.

\section{Conclusions}

Like other forms of governance, the governance of risks from natural hazards is evolving and dynamic and there is variation in the extent to which key characteristics of "new governance" have permeated risk management strategies in different nation states and regions, including those in Europe. The risk governance characterisation framework presented and discussed in this paper enables a simple, qualitative representation and evaluation of key characteristics of natural hazard governance to be produced, which can be applied in a flexible way to a variety of forms of hazard and governance setting.

We have outlined various ways of utilising the profiling tool and provided three examples to demonstrate some of the forms of comparison that can be achieved. Across these three examples we can immediately see the extent to which 
governance arrangements in just a few European settings vary between forms of hazard and between political context, sometimes strikingly so. This reinforces the need to guard against generalisations about risk governance patterns and trends in Europe and to develop a more nuanced and differentiated account of how natural hazards are being governed and the past and future dynamics involved. Use of the framework could therefore helpfully inform discussions at a European level about the scope for developing more harmonised natural hazard governance approaches, cross-border collaborations and common policy positions; and generate greater awareness of the more or less productive trends of change already underway at national and regional scales.

The profiling tool is intended to be flexible in its application and we have only begun to outline its potential. Other possibilities we have identified include its integration into expert workshop settings where representatives of different agencies or disciplines could separately produce profiles for the same hazard and compare and discuss the different or shared views and perspectives that this reveals. Another possibility could be to change the instruction from one that asks for a representation of how the current situation is seen to be, to one in which there is a representation of how governance arrangements ought to be. This then shifts the profiling from a descriptive task to a normative one in which desired objectives could be revealed and compared as a starting point for discussion of strategic objectives for the future. In these and other ways we encourage experimentation by others who see value in the characterisation framework we have developed.

At the same time it is important to recognise the limitations of the framework and what it cannot be expected to provide. Its simplicity and flexibility means that it cannot include the detail of governance arrangements that may be particularly relevant to only some forms of hazard or to some political contexts. It also necessarily defines the governance characteristics in only general terms which may be difficult to interpret and apply to specific settings. The use of qualitative scaling means that making overly precise comparisons between profiles would be problematic, but ways of addressing this could potentially be developed for specific bespoke applications of the framework.
Acknowledgements. CapHaz-Net (Social capacity building for natural hazards: towards more resilient societies) was a network project (Coordination Action) funded by the European Commission within Framework 7 Contract no. 227073. We are grateful to all participants of the CapHaz-Net workshops for their discussion of aspects of risk governance and their assistance in refining the risk governance profiling framework. Thanks to $\mathrm{M}$. Roberts and his colleagues at the Icelandic Meteorological Office (IMO) for their completion of the profiling framework; to K. Firus of T6 in Rome for arranging for the profiling framework to be completed by individuals working in the field of risk management in Italy; and to a range of other colleagues for trying out the framework. We have only reported in this paper on some of the profiles undertaken. We are very grateful to Rosie Duncan for significantly improving the diagrams.

Edited by: C. Kuhlicke

Reviewed by: two anonymous referees

\section{References}

Ahrens, J. and Rudolph, P. M.: The Importance of Governance in Risk Reduction and Disaster Management, J. Contingenc. Cris. Manag., 14, 207-220, 2006.

Bache, I. and Flinders, M.: Themes and issues in multi-level governance, edited by: Bache, I. and Flinders, M., Multi-level governance, Oxford University Press, Oxford, UK, 2004.

Beck, U.: The Risk Society: toward a new modernity, Sage, London, UK, 1992.

Bevir, M. and Rhodes, R. A. W.: Searching for civil society: changing patterns of governance in Britain, Political Administration, 81, 41-62, 2003.

Bevir, M. and Trentmann, F.: Introduction: Consumption and citizenship in the new governance, in: Governance, consumers and citizens: agency and resistance in contemporary politics, edited by: Bevir, M. and Trentmann, F., Palgrave Macmillan, Basingstoke, UK, 2007.

Bovens, M.: The social steering of complex organisations, Brit. J. Polit. Sci., 20, 91-117, 1990.

Bulkeley, H.: Governing climate change: the politics of risk society? T. I. Brit. Geogr., 26, 430-477, 2001.

Cannon, T.: Vulnerability analysis, livelihoods and disasters, edited by: Ammann, W., Dannermann, S., and Vulliet, L., coping with Risks due to Natural Hazards in the 21st Century, Taylor and Francis/Balkerma, Leiden, the Netherlands, 2006.

Chappells, H. and Medd, W. :Drought, demand and scale: fluidity and flexibility in the framing of water relations, Interdiscipl. Sci. Rev., 32, 233-247, 2007.

Christoplos, I., Mitchell, J., and Liljelund, A.: Re-framing risk: the changing context of disaster mitigation and preparedness, Disasters 25, 185-198, 2001.

Defra - Department for Environment, Food and Rural Affairs: Making Space For Water: Developing a new government strategy for flood and coastal erosion risk management in England: a delivery plan, Defra, London, UK, 2008.

Füssel, H. M.: Vulnerability: A generally applicable conceptual framework for climate change research, Glob. Environ. Change, 17, 155-167, 2007 
Hajer, M. and Versteg, W.: Performing governance through networks, Eur. Polit. Sci., 4, 340-347, 2005.

Höppner, C., Whittle, R., Brundl, M., and Buchecker, M.: Linking social capacities and risk communication in Europe: a gap between theory and practice, Nat. Haz., 64, 1753-1778, 2012.

Komac, B., Ciglič, R., Erhartič, B., Gašperič, P., Kozina, J., Orožen Adamič, M., Pavšek, M., Pipan, P., Volk, M., and Zorn, M.: Risk education and natural hazards. CapHaz-Net WP6 Report, Anton Melik Geographical Institute of the Scientific Research Centre of the Slovenian Academy of Sciences and Arts, Ljubljana, available at: http://caphaz-net.org/outcomes-results (last access: 19 October 2012), 2010.

Kuhlicke, C., Steinführer, A., Begg, C., Bianchizza, C., Bründl, M., Buchecker, M., De Marchi, B., Di Masso Tarditti, M., Höppner, C., Komac, B., Lemkowe, L., Luther, J., McCarthy, S., Pellizzoni, L., Renn, O., Scolobig, A., Supramaniam, M., Tapsell, S., Wachinger, G., Walker, G., Whittle, R., Zorn, M., and Faulkner, H.: Perspectives on social capacity building for natural hazards: outlining an emerging field of research and practice in Europe, Environ. Sci. Policy, 14, 804-814, doi:10.1016/j.envsci.2011.05.001, 2011.

Marks, G. and Hooghe, L.: Contrasting visions of multi-level governance, edited by: Bache, I. and Flinders, M., Multi-level governance, Oxford University Press, Oxford, UK, 2004.

Medd, W. and Marvin, S.: From the politics of urgency to the governance of preparedness: a research agenda on urban vulnerability, J. Contingenc. Cris. Manag., 13, 44-49, 2005.

Morrow, B.: Identifying and Mapping Community Vulnerability, Disasters, 23, 1-18, 1999.

O’Brien, K, Leichenko, R. Kelkar,U., Venema, H., Aandahl, G., Tompkins, H., Javed, A., Bhadwal, S., Barg, S., Nygaard, L., and West, J.: Mapping vulnerability to multiple stressors: climate change and globalization in India. Glob. Environ. Cha. 14, $303-$ $331,2004$.
O'Neill, J. and O'Neill, M.: Social Justice and the Future of Flood Insurance, Joseph Rowntree Foundation Viewpoint Paper, available at: www.jrf.org.uk (last access: 8 February 2013), 2012.

Pearce, L.: Disaster Management and Community Planning, and Public Participation: How to Achieve Sustainable Hazard Mitigation, Nat. Hazards 28, 211-228, 2003.

Pelling, M.: Natural disasters and development in a globalising world, Routledge, UK, 2003a.

Pelling, M.: Disaster Risk and Development Planning: the Case for Integration, Int. Dev. Plann. Rev., 25, 1-9, 2003 b.

Renn, O.: Risk Governance. Coping with Uncertainty in a Complex World, Earthscan, London, 2008.

Rhodes, R. A. W.: Understanding Governance: Policy Networks, Governance, Reflexivity and Accountability, Open University Press, Buckingham, 1997.

Rosenau, J.: Strong demand, huge supply: governance in an emerging epoch. edited by: Bache, I. and Flinders, M., Multi-level governance, Oxford University Press, 2004.

Turner, B. L., Kasperson, R. E., Matson, P. A., McCarthy, J. L., Corell, R. W., Christensen, L., Eckley, N., Kasperson, J. X., Luers, A., Martello, M. L., Polsky, C., Pulsipher, A., and Schiller, A.: A framework for vulnerability analysis in sustainability science, P. Natl. Acad. Sci., 100, 8074-8079. 2003.

UNISDR: Hyogo Framework for Action 2005-2015: ISDR International Strategy for Disaster Reduction; Building the Resilience of Nations and Communities to Disasters, United Nations Development Programme, Geneva, Switzerland, 2005.

Walker, G., Whittle, R., Medd, W., and Watson, N.: Risk governance and natural hazards, CapHaz-Net WP2 Report, Lancaster Environment Centre, Lancaster University, Lancaster, available at: http://caphaz-net.org/outcomes-results (last access: 3 January 2011), 2010. 